\title{
The Field of Near-Death Studies Through 2011: An Updated Analysis of the Scholarly Periodical Literature
}

\author{
Saharnaz Loseu, M.S., Janice Miner Holden, Ed.D., \\ and Lee Kinsey, M.S. \\ University of North Texas \\ Rozan Christian, Ph.D. \\ Dallas, $T X$
}

\begin{abstract}
Previously in this Journal, Holden and Christian (2005) profiled patterns in the field of near-death studies through an analysis of the scholarly publications from Near-Death Experiences: Index to the Periodical Literature through 2001. In this article, we provide an updated analysis of a similar type through 2011. The body of literature on which we based this analysis included 892 scholarly articles by 629 authors spanning more than a century. We report on patterns related to publication dates and venues, experts and their most cited articles, and most and least published topics in the field-both with regard to current status and in comparison to 2001 . We discuss limitations of our analysis and implications of it for the future of scholarship in the field of near-death studies.
\end{abstract}

\footnotetext{
Saharnaz Loseu, M.S., was a master's student in the Counseling Program at the University of North Texas in Denton, TX, at the time of lead-authoring this article. She has completed that degree and is currently a member of the clinical team at Genesis Women's Shelter and Support in Dallas, TX, providing counseling for victims of domestic violence. Janice Miner Holden, Ed.D., LPC-S, LMFT, NCC, ACMHP, is professor of counseling and chair of the Department of Counseling and Higher Education at the University of North Texas, Denton, TX. Her primary research interest is the transpersonal perspective in counseling with an emphasis on near-death experiences. Lee Kinsey, M.S., LPC Intern, is a doctoral candidate in the Counseling Program at the University of North Texas. His primary research interest is sexual identity development and gay issues in counseling. Rozan Christian, Ph.D., LPC-S, is in the private practice of counseling in Dallas, TX. The authors are grateful to the International Association for Near-Death Studies for a grant to update Near-Death Experiences: Index to the Periodical Literature through 2011, which provided the data for this article. Correspondence regarding this article should be sent to Ms. Loseu at sahar .loseva@gmail.com.
} 
KEYWORDS: near-death experiences; literature review; journal information; interdisciplinary research.

The field of near-death studies began formally with Raymond Moody's 1975 book, Life After Life, and a growing body of literature attests to development of the field over the intervening decades. To make the scholarly periodical literature more accessible to scholars and others conducting research on near-death experiences (NDEs) and related phenomena, the International Association for Near-Death Studies (IANDS) supported the creation and periodic updating of Near-Death Experiences: Index to the Periodical Literature (Index), the most current version of which (Holden, Christian, \& Kinsey, 2013) is available at the organization's Website (http://iands.org/research/index-to-ndeperiodical-literature.html) for IANDS members at the Supporting or higher membership level.

Nearly a decade ago, Janice Miner Holden and Rozan Christian (2005) analyzed the contents of the 2001 version of the Index to describe patterns in the field of near-death studies. Following publication of the 2011 version of the Index, we used its data to conduct a similar analysis. In this article, we report our findings, both in comparison to 2001 and to profile the current status of the field. Our analysis addresses topics including publication dates and venues, experts and their most cited scholarly articles, and most and least published topics in the field.

\section{Method}

Because data for our analysis came from the 2011 Index, we begin with a description of our method for updating the Index. Early in 2012, we conducted a search to identify scholarly publications in English from 2001 through 2011. We used electronic search engines available through the University of North Texas library, and we searched using the term "near-death experience" and variations on it. We included any article published in a peer reviewed scholarly journal that included reference to NDEs, whether or not the phenomena were the primary focus of the article. Upon identifying articles, we examined their reference lists to identify additional relevant articles. When we were confident we had exhausted our resources and had the most comprehensive listing we could compile, we counted 172 new publications for a new grand total of 892 articles, and we proceeded with analysis.

In addition to standard American Psychological Association (2011) 
citation material for each scholarly article-author, date, title, journal title and volume, and page numbers - the Index includes which of over 130 NDE-related topics are addressed in the article. The process of analyzing each article for these topics was a meticulous one in which we read each article and noted which topics were addressed. In the process of the 2011 update, we discovered the need for a few additional topics that had not been included in the prior Index versions. Four of the additional topics were Aftereffects of NDEs-Relationships ( $f a-$ milial, social); Health Care Professionals and NDEs_-Social Workers; Health Care Professionals and NDEs-Spiritual (chaplains, clergy); and Theories, NDE-related, Psychological, not otherwise specified (NOS). We also separated the topic of cross-cultural NDEs into two separate topics: Cross-cultural NDEs (outside the U.S.)-Western and Cross-cultural NDEs (outside the U.S.)—non-Western. These additions increased the number of Index topics from 134 to 139. Resultscitations broken out by components (author, year, etc.) and topics addressed in the article-were entered on an Excel spreadsheet to make the data easy to manipulate for descriptive statistical analysis.

Despite our efforts to create a comprehensive listing, we found in the course of our analysis that a few articles from 2011 were missing from the 2011 Index - probably because we conducted the original search in early 2012 before all 2011 articles had been entered into electronic search engines. Where appropriate during our analysis, we searched again to identify 2011 articles that did not appear in the Index itself; where relevant in our results below, we refer to these additional articles.

For four of the analysis topics-publication dates, venues, authors, and NDE-related topics-we sorted the spreadsheet with regard to the topic and counted entries. To identify the most cited publications, we focused on the 27 authors with the most publications and used their combined 357 publications to search Goggle Scholar for frequency of citations; with this method, we were able to collect information on $79 \%$ of the articles. For each analysis topic in the following section, we present results of our analysis followed immediately by discussion of them.

\section{Results and Discussion}

\section{Publication Rates}

To determine when and at what rates authors have produced scholarly articles in the field of near-death studies, we grouped publication dates into five-year periods through 2011; results are represented in 


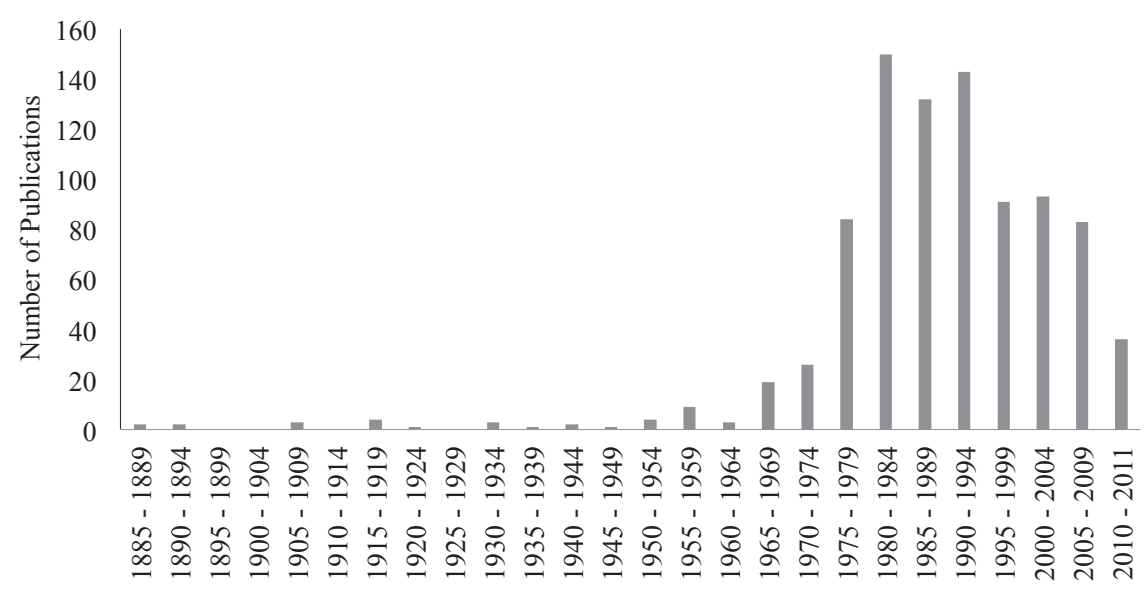

Year

Figure 1. Scholarly articles addressing near-death experiences from the earliest known in 1885 through 2011.

Figure 1. While compiling these data, we discovered that although Holden and Christian (2005) had reported the earliest article published as A. S. Wiltse's (1889), the Index actually contained Eleanor Sidgwick's (1885) four years earlier. Furthermore, in the process of pre-publication review of this article, a reviewer cited an even earlier article, which we will add to the Index when we update it next: Donnet (1866).

Although the data showed 126 years of scholarly activity in this field, nearly half of articles-48\% - were concentrated in the 15-year period between 1980 and 1995, followed by a trend of decreasing volume. However, the data also revealed that whereas 83 articles were published in the five-year period from 2005-2009 (16.6 per year on average), 36-and the number is actually somewhat higher because of 2011 articles entered in search engines after we had conducted our search-were published in just the two-year period of 2010 to 2011 (18 per year on average); thus, the average number of publications per year in recent years appears to be remaining steady if not increasing slightly. At this point, the overall profile of publication volume in the field since the 1980-1995 surge is one of decreased but fairly level productivity at a rate of just under 20 articles per year. 


\section{Publication Venues}

In addition to when scholarly NDE-related articles were published, we analyzed where they were published. We noted that 37 new periodicals joined the Index list since 2001, bringing the total number of periodicals with NDE-related publications to 184.

Table 1 shows the 29 periodicals with the largest volume of NDE-related articles, including a comparison of volume and ranking in 2011 versus 2001. In the past decade, Christian Parapsychologist and Resuscitation have joined the top-producing periodicals in this field, and the top four publication venues remained the same with a slight shift in their rank order. As both Table 1 and Figure 2 reveal, Anabiosis The Journal for Near-Death Studies/Journal of Near-Death Studies (JNDS) continues to be the leading publication venue by far, accounting for $42.6 \%$ of the total publications in the field. In the two year period of 2010 to 2011 JNDS volume approximated all other periodicals combined, with 19 versus 17 publications, respectively-though, again, the data for other publications are actually slightly higher in that we had complete data for JNDS but not for other periodicals listed in search engines in early 2011.

Fields represented by the top-producing publications continue in 2011 as in 2001: psychic/parapsychology, death/thanatology, medicine, and religion. Addition of International Journal of Engineering



Year

Figure 2. Scholarly articles 1885-2011: Anabiosis-The Journal for Near-Death Studies/Journal of Near-Death Studies versus other publication venues. 
Table 1 Top 29 Scholarly Publication Venues Ranked by Number of Articles Addressing NDEs Through 2011 and Compared to 2001

\begin{tabular}{|c|c|c|c|c|}
\hline \multicolumn{2}{|c|}{ Rankings } & \multicolumn{2}{|c|}{ Number of Articles } & \multirow[b]{2}{*}{ Periodical } \\
\hline 2011 & 2001 & 2011 & 2001 & \\
\hline 1 & 1 & 380 & 261 & $\begin{array}{l}\text { Anabiosis-The Journal for Near-Death } \\
\text { Studies }\end{array}$ \\
\hline 2 & 3 & 42 & 20 & $\begin{array}{l}\text { Journal of the American Society for Psychical } \\
\text { Research }\end{array}$ \\
\hline 3 & 4 & 29 & 19 & Journal of Nervous and Mental Disease \\
\hline 4 & 2 & 26 & 22 & Omega \\
\hline 5 & 10 & 23 & 6 & Research in Parapsychology \\
\hline 6 & 6 & 19 & 11 & Parapsychology Review \\
\hline 8 & 10 & 16 & 6 & Journal of Parapsychology \\
\hline 8 & 14 & 16 & 5 & Journal of the Society for Psychical Research \\
\hline 9 & 5 & 15 & 12 & Theta \\
\hline 10 & 25 & 13 & 3 & $\begin{array}{l}\text { Proceedings of the Society for Psychical } \\
\text { Research }\end{array}$ \\
\hline 11 & 7 & 11 & 10 & Lancet \\
\hline 12 & 8 & 10 & 9 & Journal of Religion and Health \\
\hline 14 & 14 & 9 & 5 & Journal of Religion and Psychical Research \\
\hline 14 & 9 & 9 & 8 & Journal of Transpersonal Psychology \\
\hline 15 & 10 & 8 & 6 & Death Studies \\
\hline 17 & 19 & 7 & 4 & American Journal of Psychiatry \\
\hline 17 & 14 & 7 & 5 & Journal of Humanistic Psychology \\
\hline 17 & 14 & 7 & 5 & Psychiatry \\
\hline 20 & 10 & 6 & 6 & Journal of the American Medical Association \\
\hline 20 & 37 & 6 & 2 & Resuscitation \\
\hline 23 & 19 & 5 & 4 & American Journal of Nursing \\
\hline 23 & 14 & 5 & 5 & Death Education \\
\hline 23 & 19 & 5 & 4 & Essence \\
\hline 23 & 19 & 5 & 4 & ReVISION \\
\hline 27 & 19 & 4 & 4 & American Journal of Diseases of Children \\
\hline 27 & 25 & 4 & 3 & American Psychologist \\
\hline 27 & NA & 4 & NA & Christian Parapsychologist \\
\hline 27 & 19 & 4 & 4 & Contemporary Psychology \\
\hline 27 & 25 & 4 & 3 & Journal of Scientific Exploration \\
\hline
\end{tabular}


Science and Technology and World Futures to the periodical listing indicates attention to NDEs by scholars representing an increasing range of disciplines beyond those represented in the 2001 Index.

\section{Publication Authors}

Next we examined authors in the field of near-death studies with regard to volume and currency of their publications. We dubbed the authors with the greatest volume "experts" in the field. Whereas Holden and Christian (2005) determined experts based only on sole or first authored articles, for this analysis we determined them based on any authorship: sole, first, and co-author. Thus, our 2001/2011 comparison of number of publications per author does not involve exactly the same type of data. Results appear in Table 2.

Despite our slightly different way of determining experts, the top four experts in the field remained the same with a slight shift in their rank order in the decade after 2001. Psychiatrist Bruce Greyson remained the leading expert with a total of $5.61 \%$ contributions to the body of scholarly periodical literature in the field of near-death studies. NDE investigator P. M. H. Atwater and neuropsychiatrist Peter Fenwick joined the list of top-producing authors, and four authors remained among the top producers despite their discontinuation in the field due death.

At the other end of the spectrum are authors with only one publication; their numbers almost doubled in the last decade over the previous 116 years $(1885-2001 n=360 ; 2002-2011 n=629)$. Thus, many more scholars have addressed NDEs in their publications, whether as a primary or peripheral focus. It remains for future literature analyses to determine how many of these authors remained one-time authors in the field, such as is often the case with articles based on graduate students' theses and dissertations, and whether any will become repeated contributors-even "experts"-in the field.

\section{Most Cited Publications}

We searched for citation statistics among the top-producing authors' 357 publications; results are shown in Table 3. The most cited publication in the field of near-death studies is Russell Noyes and Roy Kletti's 1977) "Depersonalization in Response to Life-threatening Danger"-cited 29 times more than top-producing author Greyson's (1983) article introducing the Near-Death Experience Scale. Both 
Table 2 Top 27 Authors of Articles Addressing NDEs Through 2011, Ranked by Number and Currency of Articles and Compared to 2001

\begin{tabular}{|c|c|c|c|c|c|c|}
\hline \multicolumn{2}{|c|}{ Rankings } & \multicolumn{2}{|c|}{ Number of Articles } & \multirow[b]{2}{*}{ Author } & \multirow{2}{*}{$\begin{array}{c}\text { Most Recent } \\
\text { Article }\end{array}$} & \multirow[b]{2}{*}{ Rank } \\
\hline 2011 & 2001 & 2011 & 2001 & & & \\
\hline 1 & 1 & 50 & 32 & Greyson, B. & $2011^{*}$ & 1 \\
\hline 2 & 2 & 26 & 25 & Ring, K. & 2004 & 13 \\
\hline 3 & 4 & 24 & 16 & Alvarado, C. S. & 2011 & 1 \\
\hline 4 & 3 & 18 & 18 & Blackmore, S. J. & 1998 & 18 \\
\hline 7 & 4 & 17 & 16 & Lundahl, C. R. & 2001 & 16 \\
\hline 7 & 4 & 17 & 16 & Noyes, R. & 1989 & 24 \\
\hline 7 & 8 & 17 & 14 & Serdahely, W. J. & 2007 & 8 \\
\hline 7 & 15 & 17 & 9 & Stevenson, I. ${ }^{1}$ & 2006 & 12 \\
\hline 9 & 17 & 16 & 8 & Holden, J. M. & 2011 & 1 \\
\hline 11 & 11 & 15 & 10 & Irwin, H. J. & 2007 & 8 \\
\hline 11 & 7 & 15 & 15 & Osis, K.1 & 1983 & 26 \\
\hline 12 & 19 & 14 & 7 & Twemlow, S. W. & 1997 & 19 \\
\hline 14 & 11 & 13 & 10 & Kellehear, A. & 2008 & 6 \\
\hline 14 & 11 & 13 & 10 & Sabom, M. B. & 2008 & 6 \\
\hline 16 & 9 & 11 & 11 & Becker, C. B. & 1995 & 22 \\
\hline 16 & 21 & 11 & 6 & Gabbard, G. O. & 1997 & 19 \\
\hline 16 & 9 & 11 & 11 & Grosso, M. & 2001 & 16 \\
\hline 19 & 15 & 10 & 9 & Greene, F. G. & 2003 & 15 \\
\hline 19 & 11 & 10 & 10 & Palmer, J. & 1979 & 27 \\
\hline 20 & 17 & 8 & 8 & Morse, M. L. & 1997 & 19 \\
\hline 24 & 35 & 7 & 3 & Atwater, P. M. H. & 2011 & 1 \\
\hline 24 & 87 & 7 & 1 & Fenwick, P. & 2007 & 8 \\
\hline 24 & 26 & 7 & 4 & Gibbs, J. C. & 2010 & 5 \\
\hline 24 & 19 & 7 & 7 & Rogo, D. S. ${ }^{1}$ & 1984 & 25 \\
\hline 24 & 24 & 7 & 5 & Roll, W. G. ${ }^{1}$ & 2004 & 13 \\
\hline 24 & 24 & 7 & 5 & Tart, C. T. & 2007 & 8 \\
\hline 24 & 26 & 7 & 4 & Walker, B. A. & 1992 & 23 \\
\hline
\end{tabular}

Note. * Latest publication listed in Index is 2010 - probably because some 2011 articles had not yet appeared in search engines when the search for Index articles was conducted in early 2012. More recent search revealed 2011 publications. ${ }^{1}$ Denotes authors who are deceased. 
Table 3 The 30 Most Frequently Cited Publications by NDE Experts

\begin{tabular}{|c|c|c|}
\hline Publication & $\begin{array}{l}\text { Frequency } \\
\text { of } \\
\text { Citation }\end{array}$ & $\begin{array}{l}\text { Average } \\
\text { Citations } \\
\text { per Year }\end{array}$ \\
\hline $\begin{array}{l}\text { Noyes, R., \& Kletti, R. (1977). Depersonalization in response } \\
\text { to life-threatening danger. Comprehensive Psychiatry, 18(4), } \\
\text { 375-384. }\end{array}$ & 212 & 5.89 \\
\hline $\begin{array}{l}\text { Greyson, B. (1983). The near-death experience scale: Construc- } \\
\text { tion, reliability, and validity. Journal of Nervous and Mental } \\
\text { Disease, 171(6), 369-375. }\end{array}$ & 183 & 6.10 \\
\hline $\begin{array}{l}\text { Noyes, R., \& Kletti, R. (1976). Depersonalization in the face of } \\
\text { life-threatening danger: A description. Psychiatry, 39, 19-27. }\end{array}$ & 169 & 4.57 \\
\hline $\begin{array}{l}\text { Osis, K., \& Haraldsson, E. (1977). Deathbed observations by } \\
\text { physicians and nurses: A cross-cultural survey. Journal of } \\
\text { the American Society for Psychical Research, 71(3), 237-259. }\end{array}$ & 154 & 4.28 \\
\hline $\begin{array}{l}\text { Greyson, B., \& Stevenson, I. (1980). The phenomenology of } \\
\text { near-death experiences. American Journal of Psychiatry, } \\
\text { 137(10), 1193-1196. }\end{array}$ & 147 & 4.45 \\
\hline $\begin{array}{l}\text { Parnia, S. F. P., Waller, D. G., Yeates, R., \& Fenwick, P. B. } \\
\text { (2001). A qualitative and quantitative study of the incidence, } \\
\text { features and aetiology of near death experiences in cardiac } \\
\text { arrest survivors. Resuscitation, 48, 149-456. }\end{array}$ & 145 & 12.08 \\
\hline $\begin{array}{l}\text { Noyes, R., Hoenk, P. R., Kuperman, S., \& Slymen, D. J. (1977). } \\
\text { Depersonalization in accident victims and psychiatric } \\
\text { patients. Journal of Nervous and Mental Disease, 164(6), } \\
\text { 401-407. }\end{array}$ & 119 & 3.31 \\
\hline $\begin{array}{l}\text { Noyes, R. (1980). Attitude change following near-death experi- } \\
\text { ences. Psychiatry, 43, 234-242. }\end{array}$ & 116 & 3.52 \\
\hline $\begin{array}{l}\text { Tart, C. T. (1968). A psychophysiological study of out-of-the- } \\
\text { body experiences in a selected subject. Journal of the Ameri- } \\
\text { can Society for Psychical Research, 62, 3-27. }\end{array}$ & 110 & 2.44 \\
\hline $\begin{array}{l}\text { Owens, J. E., Cook, E. W., \& Stevenson, I. (1990). Features of } \\
\text { "near-death experience" in relation to whether or not patients } \\
\text { were near death. Lancet, } 336(8724), 1175-1177 .\end{array}$ & 104 & 4.52 \\
\hline $\begin{array}{l}\text { Noyes, R. (1972). The experience of dying. Psychiatry, } 35 \text {, } \\
\text { 174-184. }\end{array}$ & 104 & 2.54 \\
\hline $\begin{array}{l}\text { Ring, K., \& Agar, A. (1986). The Omega project. ReVISION, } \\
\text { 8(2), 87-88. }\end{array}$ & 102 & 3.78 \\
\hline $\begin{array}{l}\text { Greyson, B., \& Bush, N. E. (1992). Distressing near-death } \\
\text { experiences. Psychiatry, 55, 95-110. }\end{array}$ & 100 & 4.76 \\
\hline $\begin{array}{l}\text { Parnia, S. F. P., \& Fenwick, P. B. (2002). Near death experi- } \\
\text { ences in cardiac arrest: Visions of a dying brain or visions of } \\
\text { a new science of consciousness. Resuscitation, } 52,5-11 .\end{array}$ & 98 & 8.91 \\
\hline $\begin{array}{l}\text { Greyson, B. (2000). Dissociation in people who have near- } \\
\text { death experiences: Out of their bodies or out of their minds? } \\
\text { Lancet, } 355(9202), 460-463 .\end{array}$ & 94 & 7.23 \\
\hline
\end{tabular}




\begin{tabular}{ccc} 
& Frequency & Average \\
of & Citations \\
Publication & Citation & per Year \\
\hline
\end{tabular}

Morse, M. L., Castillo, P., Venecia, D., Milstein, J., \& Tyler, D. C. (1986). Childhood near-death experiences. American Journal of Diseases of Children, 140(11), 1110-1114.

Blackmore, S. J. (1984). A postal survey of OBEs and other experiences. Journal of the Society for Psychical Research, 52(796), 225-244.

Greyson, B. (2003). Incidence and correlates of near-death experiences in a cardiac care unit. General Hospital Psychiatry, 25, 269-276.

Gabbard, G. O., Twemlow, S. W., \& Jones, F. C. (1981). Do "near death experiences" occur only near death? Journal of Nervous and Mental Disease, 169(6), 374-377.

Morse, M. L., Venecia, D., \& Milstein, J. (1989). Near-death experiences: A neurophysiologic explanatory model. Journal of Near-Death Studies, 8(1), 45-53.

Greyson, B. (1985). A typology of near-death experiences. American Journal of Psychiatry, 142(8), 967-969.

Pasricha, S. K., \& Stevenson, I. (1986). Near-death experiences in India: A preliminary report. Journal of Nervous and Mental Disease, 174(3), 165-170.

Ring, K., \& Cooper, S. (1997). Near-death and out-of-body experiences in the blind: A study of apparent eyeless vision. Journal of Near-Death Studies, 16(2), 101-147.

Greyson, B. (1983). Near-death experiences and personal values. American Journal of Psychiatry, 140(5), 618-620.

Stevenson, I. (1977). Research into the evidence of man's survival after death: A historical and critical survey with a summary of recent developments. Journal of Nervous and Mental Disease, 165(3), 152-170.

Noyes, R., \& Kletti, R. (1976). Depersonalization in the face of life-threatening danger: An interpretation. Omega, 7(2), 103-114.

Blackmore, S. J. (1984). A psychological theory of the out-ofbody experience. Journal of Parapsychology, 48, 201-218.

Noyes, R., \& Kletti, R. (1977). Panoramic memory: A response to the threat of death. Omega, 8(3), 181-194.

Stevenson, I., \& Greyson, B. (1979). Near-death experiences: Relevance to the question of survival after death. Journal of the American Medical Association, 242(3), 265-267.

Cook, E. W., Greyson, B., \& Stevenson, I. (1998). Do any neardeath experiences provide evidence for survival of human personality after death? Relevant features and illustrative case reports. Journal of Scientific Exploration, 12(3), 377-406. 
of these results made sense to us. In their classic article, Noyes and Kletti (1977) made a crucial and fundamental de-pathologizing point that depersonalization in response to life-threatening danger is not a psychological disorder but is actually an adaptive response, and the NDE Scale has firmly established and reconfirmed psychometrics and is by far the most-used assessment instrument in the field of neardeath studies. That the Noyes and Kletti (1977) article is cited more probably reflects, at least in part, that authors had six more years to cite it than Greyson's (1983) article.

Although JNDS proved to be the leading venue for scholarly publications in this field, it accounted for only two of the most-cited NDErelated articles, whereas the periodicals containing the most such articles were Journal of Nervous and Mental Disease $(n=5)$, Psychiatry $(n=4)$, and American Journal of Psychiatry $(n=3)$. We also found it noteworthy that 26 out of the 30 most cited publication by experts appeared in the literature prior to the year 2000 .

\section{Publication Topics}

Table 4 displays the most- and least-addressed NDE-related topics based on the number of articles dealing with those topics. Many of the top 15 topics from 2001 remain top in 2011, albeit with reordered rankings. A noteworthy exception is Explanations of NDEs-Physiological, Neurological, Brain which zoomed up to fifth place. This result reflects the recent spate of articles in which authors have attempted to explain NDEs through physical, reductionist processes-and response articles in which other authors have argued the inadequacy of such explanations to account for all aspects of NDEs.

Although the most addressed topic is methodology, this result is an artifact of our Index updating method rather than a reflection of excessive attention to this topic in the NDE literature. In our process, we indicated this topic for every article that had a "Methods" section. In our next update, we plan to revisit this categorization and restrict it to only articles in which the authors addressed some methodological process or issue in near-death studies; this revision will drastically reduce the frequency that this topic is indicated and provide a more accurate reflection of the extent to which authors address methodological issues in NDE research.

Humor About NDEs remains the least-addressed NDE-related topic in the scholarly professional literature. Although the popular literature is replete with humorous cartoons and other references to NDEs, 
Table 4 Most- and Least-Addressed NDE Topics in Scholarly Articles Through 2011, Ranked by Frequency and Compared to 2001

\begin{tabular}{|c|c|c|c|c|}
\hline \multicolumn{2}{|c|}{ Rankings } & \multicolumn{2}{|c|}{$\begin{array}{l}\text { Number of } \\
\text { Articles }\end{array}$} & \multirow[t]{2}{*}{ Topics } \\
\hline 2011 & 2001 & 2011 & 2001 & \\
\hline \multicolumn{5}{|c|}{ Most-addressed topics } \\
\hline 1 & 3 & 222 & 153 & Methodology in NDE Research \\
\hline 2 & 4 & 200 & 151 & Characteristics of NDEs-Autoscopy, Out-of-Body \\
\hline 3 & 2 & 186 & 156 & Related Experiences NOS \\
\hline 4 & 9 & 172 & 113 & Altered States and NDEs \\
\hline 5 & 7 & 168 & 120 & $\begin{array}{l}\text { Explanations of NDEs-Physiological, Neuro- } \\
\text { logical, Brain }\end{array}$ \\
\hline 6 & 10 & 160 & 112 & Afterlife, Belief in \\
\hline 7 & 8 & 156 & 119 & Characteristics of NDEs_Light, Mystical \\
\hline 8 & 1 & 155 & 162 & Characteristics of NDEs_Emotions, Pleasurable \\
\hline 10 & 13 & 143 & 101 & Circumstances of NDEs-Illness \\
\hline 10 & 6 & 143 & 125 & Explanations of NDEs-Psychological \\
\hline 11 & 11 & 137 & 110 & Disclosure of NDEs \\
\hline 12 & 14 & 135 & 100 & Science and NDEs \\
\hline 13 & 15 & 131 & 98 & $\begin{array}{l}\text { Characteristics of NDEs-Encountering Beings, } \\
\text { Deceased or Living }\end{array}$ \\
\hline 14 & 12 & 130 & 105 & Characteristics of NDEs NOS \\
\hline 15 & 15 & 123 & 99 & Aftereffects of NDEs-Orientation to Death \\
\hline \multicolumn{5}{|c|}{ Least-addressed topics } \\
\hline 128 & NA & 7 & 0 & Aftereffects of NDEs-Relationships \\
\hline 128 & 122 & 7 & 6 & Characteristics of NDEs-Sensory, Smell \\
\hline 128 & 129 & 7 & 4 & Disabilities and NDEs \\
\hline 128 & NA & 7 & 0 & Health Care Professionals and NDEs_-Spiritual \\
\hline 128 & 122 & 7 & 6 & Hypnosis and NDEs \\
\hline 128 & 122 & 7 & 6 & Religion and NDEs_-Judaism \\
\hline 132 & 122 & 6 & 6 & Famous People's NDEs \\
\hline 132 & 122 & 6 & 6 & Spiritualism and NDEs \\
\hline 135 & 131 & 5 & 3 & Characteristics of NDErs-Psychic Abilities \\
\hline 135 & 127 & 5 & 5 & Circumstances of NDEs-Combat-Related \\
\hline 135 & NA & 5 & 0 & $\begin{array}{l}\text { Health Care Professionals and NDEs_-Social } \\
\text { Workers }\end{array}$ \\
\hline 135 & 132 & 5 & 2 & Religion and NDEs_-Islam \\
\hline 137 & 129 & 4 & 4 & Artificial Intelligence and NDEs \\
\hline 138 & 132 & 2 & 2 & Circumstances of NDEs-Induced Non-chemically \\
\hline 139 & 134 & 1 & 1 & Humor About NDEs \\
\hline
\end{tabular}


scholars have largely ignored this subject-apparently continuing to consider NDEs no laughing matter.

Holden and Christian (2005) had commented that least-addressed topics related to religion represented both fertile and important topics in the field of near-death studies. We were heartened at the result from the 2011 Index that articles on NDEs and Islam and Judaism had increased since 2001 but disappointed that these topics have remained among the least-addressed in the field. Our reaction was similar regarding the topic of combat NDEs: glad to see additional attention during the past decade but sad that authors did not pay even more attention to this topic considering the burgeoning of returning veterans in the U.S. during the past decade, many of whom undoubtedly have experienced NDEs. Similarly, considering the importance of healthcare providers' responses to NDE disclosure to experiencers' trajectories in integrating their NDEs, we were encouraged that Disclosure of NDEs remained among the most-addressed topics but concerned that Health Care Professionals and NDEs-Spiritual and - Social Workers were among the least-addressed topics; again, we believe these latter topics deserve increased attention in the professional NDE literature.

\section{Summary}

Based on results of this analysis of the 2011 Index to the scholarly NDE-related periodical literature, the past decade has been marked by an expansion of the field of near-death studies through attention to NDEs by authors new to the field and by publication venues new to the listing since 2001. Greyson remains the leading scholar in the field of near-death studies with the greatest volume of publications and the second-most-cited article in the field. JNDS, as the single greatest publisher of scholarly NDE periodical literature, remains an important presence in the field, despite the fact that most citations are of articles that were published in other periodical venues. It is our hope that authors in the future devote even more attention to various important yet seemingly neglected NDE-related topics to remove them from the ranks of least-addressed topics in the field.

It is also our hope that IANDS will continue to fund periodic updates of the Index; if they do, it is our intention to publish future installments profiling the evolution of the field of near-death studies from the scholarly periodical literature. Other topics we may address in the future are which institutions of higher education are most active in 
producing scholarship in the field and-crucial to advancement in the field-sources of funding for NDE-related research and publications.

\section{References}

American Psychological Association. (2011). Publication manual of the American Psychological Association (6 ${ }^{\text {th }}$ ed.). Washington, DC: Author.

Donnet, C. A. (1866). Premature interment. Lancet, 1, 295-296.

Holden, J. M., \& Christian, R. (2005). The field of near-death studies through 2001: An analysis of the periodical literature. Journal of Near-Death Studies, 24, 21-34.

Holden, J. M., Christian, R., \& Kinsey, L. (2013). Near-death experiences: Index to the periodical literature through 2011. Available at International Association for Near-Death Studies website, http://iands.org/research/indexto-nde-periodical-literature.html. Durham, NC: International Association for Near-Death Studies.

Sidgwick, E. M. (1885). Notes on the evidence, collected by the Society, for phantasms of the dead. Proceedings of the Society for Psychical Research, 3, 69-150.

Wiltse, A. S. (1889). A case of typhoid fever with subnormal temperature and pulse. Saint Louis Medical and Surgical Journal, 57, 355-364. 